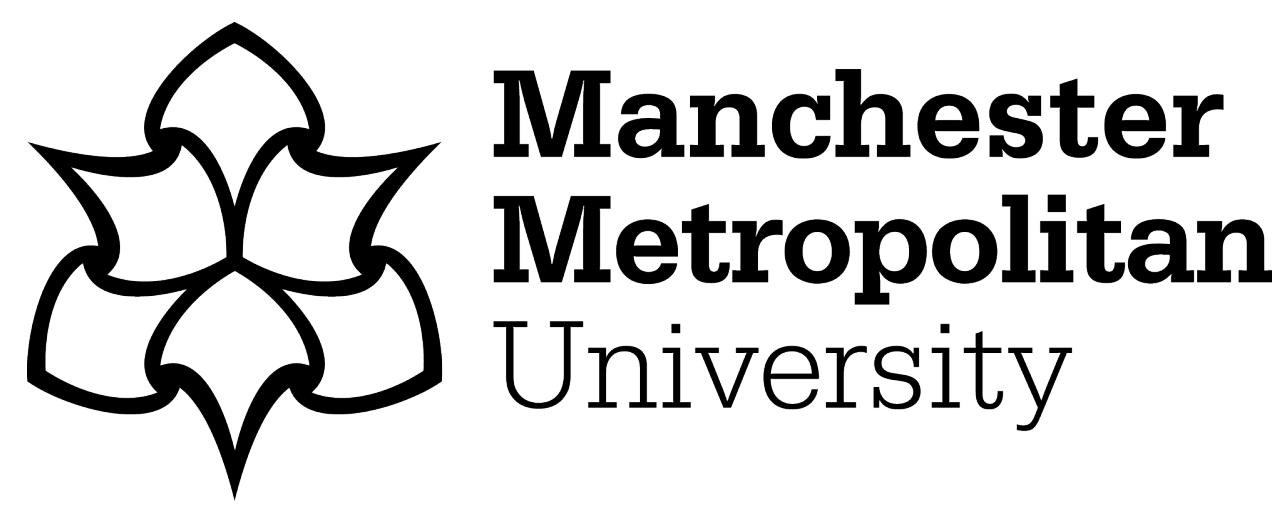

Kuntsman, Adi ORCID logoORCID: https://orcid.org/0000-0002-9970-9866 and Miyake, E ORCID logoORCID: https://orcid.org/0000-0001-5504-7648 (2019) The Paradox and Continuum of Digital Disengagement: Denaturalising Digital Sociality and Technological Connectivity. Media, Culture and Society, 41 (6). pp. 901-913. ISSN 0163-4437

Downloaded from: https://e-space.mmu.ac.uk/623117/

Publisher: SAGE Publications

DOI: https://doi.org/10.1177/0163443719853732

Please cite the published version 


\title{
The paradox and continuum of digital disengagement: denaturalising digital sociality and technological connectivity
}

Adi Kuntsman Esperanza Miyake

\begin{abstract}
This theoretical intervention puts forward a concept of 'digital disengagement' to discuss new socio-cultural, economic and political demarcations and implications surrounding the relationship between digital media, culture and society. At present, despite a proliferation of calls to reduce both the range of digital devices and communication platforms, and the time spent using them, and despite a growing body of academic work on disconnection or opt-out, disengagement from the digital is still conceptualised by media research as a spatiotemporal or an ideological aberration. To challenge this framework, we propose a paradigmatic shift. We invite digital media scholarship to denaturalise the digital by centring digital disengagement both as a complex phenomenon currently unfolding and as a conceptual entry point into thinking about sociality, agency, rights and everyday life more broadly. Mobilising digital disengagement as a theoretical lens, our piece provides the following: first, we critically assess the prevalent conflation of digitality with social networking, which leads to a limited understanding of disengagement as being only about disconnecting from social media platforms. Second, we challenge the normalisation of the technological in practices of disconnection, arguing instead that disengagement might be structured, but should not be determined, by the technological.
\end{abstract}


Third, we demonstrate that digital disengagement is not a single phenomenon but a complex continuum of practices, motivations and effects. Understood as such, it has the potential to open new ways of imagining relations between technologies and freedoms, engagement and digitality and sociality and refusal.

\section{Keywords}

dataisation, digital disengagement, disconnection, Facebook, Internet centrism, Internet of Things, neoliberalism, non-use, opt-out, social networking sites

\section{Introduction}

Today, digital communication technologies are increasingly embraced by industries, governments and everyday users. As both people and public services are imagined as digital or networked 'by default' (Fotopoulou, 2014; GOV.UK, 2013, 2017), engagement - whether civic, consumerist or otherwise - is now predominantly understood as digital. Those disconnected from the digital are seen as 'at risk' of being 'left behind' (Helsper and Galacz, 2009; Straumann and Graham, 2016). And yet, we are also witnessing a proliferation of calls to reduce both the range of digital devices and communication platforms, and the time spent using them, issued by those who are already connected and digitally savvy. Bloggers write about putting down their phones to (better) connect to family and friends. Activists seek ways to resist platform labour or evade state, corporate and social media surveillance by switching off and/or moving to alternative forms of communication. Populist experts warn about 'digital addiction', to which businesses respond with commercial packages offering 'digital detoxes'. Initiatives such as 'digital diets' and 'unplugging days' are mushrooming.

Whether we understand those as a rebellion against the growing power of digitisation, or as a neoliberal retreat into a 'better life', we must seriously consider them as an invitation to rethink the conceptual normalisation of the digital. Scholarship of digital media and society has long focused on various forms of engagement with digital communication technologies, devices and platforms, be those on macro or micro level, positive or negative: for example, by looking at the ways we deploy social media as activists, educators and learners, workers or consumers; or the ways we use and interact with digital platforms and communication devices in public, semi-public and private spaces; or the ways we live with 'smart' technologies that are near, on or inside our bodies. Dis-engagement from the digital, however, is rarely considered as anything but an aberration, whether temporal, demographic or even ideological. To challenge this framework, our article proposes a paradigmatic shift. We invite digital media scholarship to denaturalise the digital by centring digital disengagement both as a complex phenomenon currently unfolding and as a conceptual entry into thinking about sociality, agency, rights and everyday life more broadly.

\section{Denaturalising the digital}

Calling for a more critical approach to digitality and the contemporary compulsion to unnecessarily 'fix things' in our daily lives through technologies and digital mediation 
- what he calls 'technological solutionism' - Evgeny Morozov (2013) relates this modern day propensity to what he describes as 'Internet-centrism'. Referring to 'smart' technologies as offering solutions to remedy 'flawed' human conditions from obesity, environmental issues, to fitness, Morozov (2013) argues that integral to the idea and ideological state of 'Internet-centrism' is an underlying core belief that the Internet is 'the ultimate technology and ultimate network' (p. 23, emphasis ours). Hence, 'solutionists' can find even more ways to 'solve problems' enabled by the Internet, through technological and networked mediation.

Morozov's statement on 'Internet-centrism' reveals a general problematic trend within academic and popular discourses concerning 'the digital'. Following Morozov, we argue that not only has the Internet become the main basis for understanding digitality, but also, 'the digital' as a term and concept has become inseparably yoked to technologised and networked practices, societies, cultures and geographies. This naturalisation of the digital as being necessarily networked has meant that any discussion regarding digital citizenship, identities, cultures and practices has always been about connective/disconnective practices to technology and networks - and increasingly so, social networks.

In other words, there is a further collapsing between the concept of technology and networks in themselves, where even Morozov (2013) conceptualises 'smart' technologies as being an inseparable and an integral part of networked social connectivity (p. 3). Such a fusion of technology and networks has become even more pertinent with the increasing integration of online and offline systems, smart and sensored devices, where technologies are increasingly social, communicating with one another and belonging to a networked material community almost independent of human agency and intervention. While we agree with such theoretical configurations of digitality as being inevitably technological and/or networked on one hand, we also want to, on the other hand, problematise, destabilise and denaturalise the link between digitality, sociality and technology. This is particularly important, as we turn to the growing body of work that has developed since early 2010s around digital refusal, withdrawal and other forms of nonuse.

\section{Rethinking digital disengagement as (merely) a social refusal}

With only a few publications focusing specifically on devices such as tablets and smartphones (Emek, 2014; Mowlabocus, 2016), most research to date attends to digital disengagement in relation to online communication, with a heavy emphasis on social networking, especially Facebook (Baumer et al., 2013; Gershon, 2011; John and DvirGvirsman, 2015; Karppi, 2011; Light, 2014; Portwood-Stacer, 2012a, 2012b, 2012c, 2013, 2014). This is true not only for the body of published work, but for the overall academic discourse. A conflation of the 'digital' with 'SNS' is a reflection of the pervasive nature of social networking, beyond the wide-spread use of actual platforms and its consequence theoretical understanding within academia. The increasing normalisation of the digital, coupled with the simultaneous social mediafication of all areas in our lives, has two implications for academic research that we wish to challenge.

First, we argue that we need to question the ways digital disengagement has become inseparable with the idea of social disengagement. Within such a formulation, the digital 
and the social collapse into a singular, interchangeable concept leading to what Light (2014) described as 'disconnective practice' which involves 'potential modes of disengagement with the connective affordances of SNSs in relationship to a particular site, between and among different sites and in relation to the physical world' (p. 17). In other words, digital connectivity and engagement are defined and naturalised through the concept of social practice. In this context, withdrawal from it - the practice digital disengagement - becomes concerned with the resulting issues and consequences upon users' social relationships (friends, partners, family and work). We argue that digital disengagement can refer to 'disconnective practices' from social networking and also that the concept of the digital itself must first be divorced - denaturalised - from the question of social engagement and social networking. Only then can we begin to open up new ways of thinking about digitality and the ways digital disengagement might have other, broader, social and political implications.

Second and related, an additional conflation resulting from the naturalised link between digitality and sociality, which we wish to challenge, is the dominance of Facebook as the social networking site for digital disengagement. With the exception of a few studies like Sasaki et al. (2016) examination of 'unfriending' and processes of digital disengagement on Twitter, very few scholars to date discuss digital disengagement on other social networking platforms such as Instagram, Pinterest, Snapchat, Tinder, Tumblr, Twitter, YouTube or Whatsapp. Even in Light's (2014) work that explores the migration of disconnective practices played out across various social networking platforms, both the results and discussion indicate that Facebook is almost always the starting and comparative reference point where it is presented as the dominant standard of all social networking platforms. Empirically, it might be because for many, Facebook has become an environment which ruins and damages, rather than fosters and supports social connections. Conceptually, however, the result is that digital disengagement becomes tied to not only social disengagement but also to Facebook disengagement. Within this context, digital disengagement can only be understood if the concept of the digital is aligned to sociality and networked connectivity, and by the same token, sociality is tied to Facebook as a prime communication platform. What does digital disengagement look like on Instagram? Can Facebook ever be the secondary or even tertiary social networking site people migrate to rather than from having disengaged elsewhere? And more importantly, what are other forms of digital disengagement, beyond social networking?

\section{Rethinking the normalisation of the technological}

Thinking about possibilities of disengaging 'elsewhere', we return to Morozov's (2013) critical call to unlearn solutionism and rebel against its value systems (p. xv). Here, moving beyond disconnection from social networking, we take a critical look at the current normalisation of digital platforms and devices themselves.

When 'Cyber' Studies first rose to Euro-American academic prominence during the 1990 s to early 2000s, one of the key concerns at the time was how 'the digital' was forcing us to re-conceptualise issues surrounding (de)materialisation. Increasing importance was placed on coding, data and software - to a point where 'consumption of commodity occurs through coding' (Mackenzie, 2005: 86) - where material technologies were 
becoming obsolete. A decade or so later and 'the digital' has not only overtaken technological materiality, but seems to have gone past itself into 'the algorithmic'.

The recent body of work within digital studies has been moving steadily towards the move from 'the digital' to 'the algorithmic' (Noble, 2018), where digital economies, politics, culture and societies are increasingly tied to deterministic and predictive flows and movement of 'lively data' (Lupton, 2015). But inasmuch as scholars (Berry, 2011; Dodge and Kitchin, 2011; Manovich, 2013) have focussed on codes, algorithms and online data, there is return to questioning the role of technology, especially with the everyday proliferation of 'smart' devices. In a digital neoliberal era obsessed with metrics and tracking - the self, others, space/time, productivity and engagement - contemporary life is becoming technocentric again. As Elwell (2014) argues, 'computing is folding the material world itself' (p. 233) into an Internet of Things that 'merges physical and computational infrastructures into an integrated habitat' (Weiser, 1998: 41-42). Our need for smart technologies that rely on integrated and sensored material systems means that technological materiality - or a New Materialism (Lupton, 2016) - is now at the forefront of academic debate (Bunz and Meikle, 2018; Greengard, 2015).

In other words, it is not just us humans living with and in media - as argued by Deuze (2012) - but it is also technological 'things' that live with and in media. Such a theoretical standpoint begins with the idea that people have become entangled in assemblages of objects, described by Lupton (2016) as 'human-body-device-sensor-software-data configuration'(p. 33). If such integrated systems organise our personal, work and social lives, is it even possible to practice digital disengagement? What does non-digitality mean? How can we divorce digitality from technology? Or does digital disengagement merely sustain the dominance of the mediated and the technological?

The illusion that we can comprehensively control our media (for example by pulling the plug, pressing the off switch on a remote control, by becoming mediawise and developing sophisticated media literacies) in fact preserves media as the primary definer of our reality. (Deuze, 2012: xiii)

Deuze's (2012) statement resonates with Morozov's (2013) ideas on technological solutionism and Internet-centrism as we have outlined earlier. By being 'mediawise' which inevitably involves more media - in order to 'escape' digitality, we simply keep preserving digital technologies and its operating systems as, indeed, an Internet-centric, 'primary definer of our reality'. Instances of unintentional technological preservation can be seen everywhere: from the 'Moment' app which helps users manage screen time, to an anti-surveillance device called 'Cyborg Unplug' (n.d.), which 'detects and disconnects selected devices known to pose a risk to personal privacy'. Within a similar technologic, we witness smart houses that involve tasking technology to limit or disconnect another technology. In effect, our day-to-day living environments are increasingly designed to delegate human agency - including the practice of digital disengagement onto digital technologies. We are fast becoming agents simply acting as communication vessels between devices, executioners of an all-encompassing digital and technological solutionist world. In other words, as 'smart' technologies become 'smarter' and rely on networking communities through networked devices, it is imperative we do not similarly 
conceptualise the digital in ways that normalise the connection between ontological materiality, human agency and technological determinism. In an era where the Internet of Things is 'not just about networked sensors being fitted to things but how these things gain new skills that are expressed in new forms of communication' (Bunz and Meikle, 2018: 1) - in other words, when multiple devices are communicating with each other can disconnection from one piece of technology really equate to digital disconnection as a whole?

\section{Digital disengagement: a continuum}

Inspired by the two questions we raise -how can we think about digital disengagement beyond social media, and beyond a particular piece of technology? - we now turn to actual examples of digital disengagement, as those are captured by a small but rapidly growing body of scholarship on the subject. We will demonstrate that the range of motivations, practices and experiences and the richness of both popular and academic vocabularies used to describe them - disconnection, withdrawal, opting out, leaving, non-use, non-participation, detox, unplugging, suicide and more - point to what we coin a continuum of digital disengagement. Imagining disengagement as a continuum challenges the one-dimensional understanding of digital refusal and its effects while simultaneously unravelling and refiguring the collapse of the 'digital' into a particular technology, platform or form of sociality.

\section{A continuum of practices}

Against a fixed dichotomy of being either connected or disconnected, recent research point to a diverse range of experiences and practices that are involved in disengaging. For example, in their discussion of mediated political action, Casemajor et al. (2015) distinguish between passive non-participation (inability to use technology due to incidental or imposed reasons) and active non-participation as 'politically wilful engagement in a platform in order to disrupt it' (refusing to provide platforms personal data or using platforms against its original aims; p. 856). Here, active non-participation, and especially deliberate departure, equates to resistance and refusal - akin to Facebook suicide as a form of protest (Karppi, 2011). However, deliberate disconnection can also be seen as something positive that 'adds value to our engagement with SNS' (Light, 2014: 20-21). Furthermore, many instances of disengagement are both 'active' and 'passive', transgressive and reaffirming, or rather, they are multi-dimensional, because they might involve the conscious decision to withdraw - physically, emotionally, socially and so on - from certain normative spaces and forms of sociality and behaviour while also having the ability to negotiate one's connection to and through technology.

Furthermore, practices of digital disengagement are rarely total and unidirectional: with an exception of dramatic and one-time events such as 'Facebook suicides', digital disengagement described in the current research is seldom about a one-off moment. Nor is it necessarily about steadily moving further and further away from the digital. Baumer et al. (2013) note 'resisting, leaving, relapsing, and limiting' as four main practices of not engaging with Facebook, where 'relapsing' refers to returning after a 
period of non-use. Such a return can occur due to changing one's decision because of personal reasons or peer pressure; or perhaps because the disconnection itself was timespecific; or because, as our own interviews revealed, the pressure of the labour market, where one can be required to use social media at work (Kuntsman and Miyake, 2015; Portwood-Stacer, 2014).

The multi-directionality of digital disengagement occurs across time and space, responding to changing pressures of digital use. Light's (2014) work on 'disconnective practice' is particularly interesting here as he discusses 'personal level of disconnection' and disconnection at work or in public space outside of home and work. The multiplicity of disengagement indeed needs to be understood as dynamic and situational. As Light (2014) puts it, '[d]isconnective practice [...] involves potential modes of disengagement with the connective affordances of SNS in relationship to a particular site, within a particular site, between and among different sites and in relation to the physical world' ( $p$. 17). However, importantly, this multi-directionality is also structural: whether it is the socio-cultural structure of demands of connectivity that create a pressure to return (Van Dijck, 2013); or the economic system within which such a return might be enforced at any time after disengagement - and then renegotiated again; or the structure of a platform itself. As Karppi (2011) has noted in his discussion of Facebook suicide, disconnection is never fully possible, not only because leaving itself is premediated and controlled by Facebook but also because the data left behind continues to be used by the platform. Karppi's early note of caution regarding the power of platform and data aggregation, and the limitations of human resistance, is acutely relevant today, when algorithms and data mining infringe powerfully and persistently on individual and collective freedoms. ${ }^{1}$

Following Karppi, it is worth noting that digital disengagement involves both human and non-human actors, as also recently argued by Light (2018). But if Light suggests that disconnection can be temporarily and spatially enforced by objects - for example, the quality of Wi-Fi connection that can be disrupted by built environments - Karppi's work reminds us that platforms and digital data itself, as non-human actors, can be ones that determine our im/possibilities of escaping the digital.

\section{A continuum of motivations}

Portwood-Stacer (2012a) noted three main themes with regard to media refusal. One of them is the notion of addiction to media (and a moral panic around it) - a discourse that places pathologisation at its centre, with digital addition as something to be diagnosed and 'fixed'. This discourse simultaneously centres the experts who offer solutions and perpetuates 'individual responsibilisation' where the user, rather than the digital economy or the culture of compulsory connectivity, is held responsible. The other theme is asceticism and self-transformation in abstinence from the digital (Portwood-Stacer, 2012b), which combines religious metaphors with capitalist notions of self-discipline and productivity. And finally, Portwood-Stacer (2012c) notes aesthetics and taste, as a cultural performance of class distinction, which shaped stories of media refusal. In our own past research and similar mapping on digital disengagement (Kuntsman and Miyake, 2015), we noted overlapping key themes: concern over the monitoring and state/corporate surveillance; the disappearance of 'human connection' or 'quality time'; the impacts 
on emotional, psychological, physical, mental and spiritual health; financial costs and excessive materialism; and environmental concerns.

What is perhaps most striking in all these findings is not merely the variety of motivations, but their 'qualitative' difference: while some are individualised and self-centred, others are driven by collective, social and political concerns. The latter, in particular, carry a potential to undo the centrality of digital media in our lives, for example, by calling to actively resist and sabotage digital platforms (Andersson, 2016; Casemajor et al., 2015), or by refusing social media participation to protest exploitative labour (PortwoodStacer, 2014) or by rethinking the environmental sustainability of current digital practices (Kuntsman and Rattle, 2019). The former, however, often result in temporary withdrawal in ways that only supports the dominance of digital sociality: 'unfriending' some people on Facebook (Gershon, 2011; John and Dvir-Gvirsman, 2015), reducing the use of devices on holidays in order to resume their 'regular' use upon return (Mowlabocus, 2016) or 'relapsing' after leaving (Baumer et al., 2013).

\section{A continuum of effects}

Conceptualising disconnection and disengagement as a continuum of motivations many of which differ by cultural, social, linguistic and political contexts and are yet to be explored in depth - makes it clear that this phenomenon should not be understood as always and necessarily transgressive, especially when acts of digital dissent rely paradoxically on digitalities and technologies themselves. Furthermore, while disconnection may begin as a form of resistance, it can also become appropriated. However, similarly, we should not dismiss digital disengagement as merely a form of neoliberal compliance or a trendy new indulgence. ${ }^{2}$ What we propose, instead, is to think about disengagement as a continuum of multiple possible effects.

Furthermore, the range of platforms, data and other non-human actors opens up a different thinking about engagement and disengagement which may be structured, but is not fully determined, by the technological. The continuum of digital disengagement is multidimensional, because each instance of disengagement is located at various points of the spatiotemporal continuum. Such a continuum links our off- and on-line everyday practices as structured and orchestrated by socio-technological environment; socio-political effects such as protest, resistance, compliance and co-optation; and, finally, by the human/nonhuman web of actors. All of these impact both our theorising of agency and our legal and political horizons of rights and freedoms with regard to the digital. The continuum of digital disengagement, in other words, is an invitation to imagine new possibilities of relations between technologies and freedoms, engagement and digitality and sociality and refusal.

\section{Digital disengagement and its paradoxes}

Concluding their discussion of non-participation and the question of resistance, Casemajor et al. (2015) write about the paradox of non-participation, noting that '[a] conclusive exit from the digital spheres entirely, in an ultimate bid to resist surveillance or capture, might also pre-emptively deny any possibility of an internal engagement which might positively configure technologies toward desirable forms of participation' (p. 863). Indeed, a 
concern about 'missing out' on more promising forms of digital participation, or on the opportunities to change digital cultures from within is often linked to a more philosophical question of 'what form of free will can be exercised by not participating' (Casemajor et al., 2015: 864). Such a stance is one that often forms the basis for critique against digital disengagement. At the heart of such a question, however, lies the naturalisation of engagement as digital, which we have challenged throughout this article: an assumption about inherently positive possibilities of digital technologies and a conflation of digital technologies with sociality and social participation. Furthermore, the distinction between participation and non-participation itself seems to be dichotomous, which, as we have argued, is far more nuanced and multi-spatiotemporal. What we demonstrated throughout this article is that disengagement is a continuum and, as such, the way to the outside of the digital is seldom unidirectional, and rarely straightforward.

We want to intervene here with another paradox entirely. Not a lost opportunity to engage differently, but an impossibility to disconnect beyond the digital; or rather, a circular return to it: the very digital and material architectures of our networked society and devices ensure that we remain embedded within its structure, becoming the mediators of on- and off-line synchronisation between the Internet and its 'smart' devices. In addition, the culture of compulsory digital sociality follows suit. Individuals writing about the need to reduce digital consumption ironically use their very computers, social media and the Internet to spread the word about their intentions. ${ }^{3}$ The loop of digitality intensifies further in collective initiatives dedicated to disengagement, where users are encouraged to get off-line but stay in touch through email subscriptions and social media and sometimes even to explicitly report back on their experience of disconnection. For example, the website of the US-based initiative 'National Day of Unplugging' (n.d.) asks people to pledge to 'unplug', but come back later with a selfie showing their unplugging 'pledge'. Mobilising the 'selfie genre' is particularly ironic, since selfies have become the epitome of today's social media engagement (Kuntsman, 2017; Senft and Baym, 2015). Asking participants to unplug while inviting them to upload the evidence of unplugging online demonstrates the pressure to validate acts and experiences of 'goodness' through online verification. Such practices of prosumption (Ritzer, 2015; Ritzer and Jurgenson, 2010) are part of the process of self-production and self-presentation for the active disengager: digital disengagement itself becomes a tool for online self-promotion. The structure of participation such as this one, as well as the ever-present pop-ups demanding that the website user 'stays in touch' and 'does not miss out', result in potential disengagers being encouraged to ultimately return back to the digital as part of the supposed ethical and political stance of converting individual acts into a communal digital refusal.

We can, indeed, read this circular trap as part of what Van Dijck (2013) called the normative 'culture of connectivity', where even the disconnection itself is practised through a form of connection. However, the key aspect here, rather, is the digital labour (Fuchs, 2013; Scholz, 2013) involved in online performances of disconnection. The selfpromoting disengager, who returns online to tell the story of having unplugged, is providing free content for the website which promotes disengagement. User-generated content (selfies, stories, comments, etc.) on such websites mean that digital disengagement is not only a temporary technopractice, from which one has to come back and 
report, but one whose ongoing work is essential to sustaining the very world of digitality it is trying to oppose. Without the selfies, the stories and the comments, there would be no followers, no sharers and no visitors to these websites.

It is by understanding digital disengagement as embedded in the capitalist, neoliberal mode of digital communication as depended on users/prosumers' ongoing labour, that another paradox becomes clearer: the paradox of digital solutionism (indeed, following Morozov's 'Internet solutionism') for digital withdrawal. We can witness a rise in various enterprises offering digital tools to help step away from the digital, in order to effectively manage one's own time. In addition to various 'life coaching' services offered on- and off-line, there is now a plenitude of apps for everyday management of technology. Specific settings and timers enable users to control, regulate, manage and monitor their screen time and information overload. The apps position themselves as aids in reducing the digitality of the everyday; however, in fact, these are tools of disciplining a productively labouring subject, one that manages their time effectively, works without distraction and rests well in order to return to an even higher productivity - all with the help of the latest digital solution.

But perhaps the most important paradox of digital disengagement lies in the illusion of choice that frames every act of refusal, disconnection or opt-out. Whether understood as a conscious protest or an ordinary gesture, an individual decision or a collective initiative, digital disengagement presumes human agency - and at least a possibility of success. And yet, the decision about disengagement is never truly ours. Consider, for example, the UK Government's policy of 'digital by default' (GOV.UK, 2013) and its related 'transformation strategy' of promoting digital investment into businesses, services and skills (GOV.UK, 2017). The move towards the digital becoming the default means, first and foremost, pushing out and disinvesting from other, non-digital skills and services, leading to the difficulty, and eventually to the impossibility, of opting out of the digital. Furthermore, the reference to a 'better use of data' reminds us that in today's environment of compulsory datafication and verification, we have little control over our data to begin with - and because of the ways data ownership, mining and analytics are structured, individual self-exclusion of a particular device or service does not change one's ultimate integration onto governmental and corporate webs of data. And when 'smart things' are everywhere, and always already networked, one's possibility of escaping the digital - in shared private, as well as in public spaces, in education and healthcare, in public transport and border controls - is diminishing rapidly.

How, then, can we move away and beyond these paradoxes? We do not have a solution, nor do we believe one solution would be enough, neither in theory nor in policy or design - even though legislative initiatives such as the recent European General Data Protection Regulation are most welcome developments in protecting some digital rights, of some citizens, in some contexts. What we suggest, instead, is that we use digital disengagement as a starting point, as a political and empirical anchor, from which each digital formation, each policy and each conceptualisation is evaluated. Only then, perhaps, we would be able to move away from both normalised digitality and the pervasive nature of technological solutionism. Only then, perhaps, would we decouple our imaginaries of sociality from those of digital social networking. Only then, perhaps, we would imagine the right to opt-out not as an aberration, not as a paradox, but as one possible norm. 


\section{Funding}

The author(s) received no financial support for the research, authorship and/or publication of this article.

\section{Notes}

1. Recent revelations around Facebook data brokering and data aggregation and the existence of 'shadow profiles' for individuals who do not even have Facebook accounts is a striking example of the dangers Karppi had alerted to.

2. It is important to emphasise, however, that it takes privilege to opt out, as Portwood-Stacer (2014) rightly argues (see also Marwick, 2011; Scholz, 2013), and as we suggest in our own analysis of various businesses that support digital disengagement (Kuntsman and Miyake, 2016).

3. For an example, see https://medium.com/@richardjeaton/ive-been-on-a-digitaldetox-blog35-of-my-100blogs-c7905bbe0876. Related to this is also a paradox of methods: what is the role of digital tools - programmes for data mining or qualitative analysis, or even Google search - in researching those who wish to leave the digital realms? Is it ethical to deploy digital search for someone who does not want to be found? Is it wise to forego digital tools of data management in a project on digital disengagement? Arriving independently to the same dilemma, Hesselberth (2018) notes that scholarly methods of researching disconnectivity are at odds with the gesture of disconnectivity itself.

\section{ORCID iD}

Adi Kuntsman (iD https://orcid.org/0000-0002-9970-9866

\section{References}

Andersson L (2016) No digital 'castles in the air': online non-participation and the radical left. Media and Communication 4(4): 53-62.

Baumer E, Adams P, Khovanskaya V, et al. (2013) Limiting, leaving, and (re)lapsing: an exploration of Facebook non-use practices and experiences. In: SIGCHI conference on human factors in computing systems, Paris, 27 April-2 May, pp. 3257-3266. New York: ACM.

Berry D (2011) The Philosophy of Software: Code and Mediation in the Digital Age. Basingstoke: Macmillan.

Bunz M and Meikle G (2018) The Internet of Things. Cambridge, MA: Polity Press.

Casemajor N, Couture S, Delfin M, et al. (2015) Non-participation in digital media: toward a framework of mediated political action. Media, Culture and Society 37(6): 850-866.

Cyborg Unplug (n.d.) Available at: https://plugunplug.net/ (accessed 1 June 2016).

Deuze M (2012) Media Life. Cambridge, MA: Polity Press.

Dodge M and Kitchin R (2011) Code/Space: Software and Everyday Life. Cambridge, MA: The MIT Press.

Elwell JS (2014) The transmediated self: life between the digital and the analog. Convergence 20(2): 233-249.

Emek M (2014) Digital detox for the holidays: are we addicted?. Available at: http://openaccess.dogus.edu.tr/xmlui/bitstream/handle/11376/1059/MehmetEmek_CorrectedPaper. pdf? sequence $=3$ \&isAllowed=y (accessed 1 December 2017).

Fotopoulou A (2014) Digital and networked by default? Women's organisations and the social imaginary of networked feminism. New Media and Society 18(6): 989-1005.

Fuchs C (2013) Digital Labour and Karl Marx. London: Routledge. 
Gershon I (2011) Un-friend my heart: Facebook, promiscuity, and heartbreak in a Neoliberal Age. Anthropological Quarterly 84(4): 865-894.

GOV.UK (2013) Government digital strategy: reports and research. Available at: https://www. gov.uk/government/collections/government-digital-strategy-reports-and-research (accessed 1 November 2017).

GOV.UK (2017) Government transformation strategy 2017 to 2020. Available at: https:// www.gov.uk/government/publications/government-transformation-strategy-2017-to-2020 (accessed 1 November 2017).

Greengard S (2015) The Internet of Things. Cambridge, MA: The MIT Press.

Helsper EJ and Galacz A (2009) Understanding the links between digital engagement and social inclusion in Europe. In: Cheong A and Cardoso G (eds) World Wide Internet: Changing Societies, Economies and Cultures. Taipa, Macao: Macao University Printing House, pp. 146-178.

Hesselberth P (2018) Discourses on disconnectivity and the right to disconnect. New Media and Society 20(5): 1994-2010.

John N and Dvir-Gvirsman S (2015) 'I don't like you any more': Facebook unfriending by Israelis during the Israel-Gaza Conflict of 2014. Journal of Communication 65(6): 953-974.

Karppi T (2011) Digital suicide and the biopolitics of leaving Facebook. Transformations. Available at: http://www.transformationsjournal.org/journal/issue_20/article_02.shtml (accessed 1 October 2016).

Kuntsman A (ed.) (2017) Selfie Citizenship. Basingstoke and New York: Palgrave Macmillan.

Kuntsman A and Miyake E (2015) Paradoxes of digital dis/engagement: Final report. Working Papers of the Communities \& Culture Network+, 6. Available at: http://eprints. whiterose. ac.uk/114806/ (accessed 21 May 2019).

Kuntsman A and Miyake E (2016) Paradoxes of digital dis/engagement: a follow up study (businesses and services). Working Papers of the Communities \& Culture Network+, 7. Available at: http://eprints.whiterose.ac.uk/114828 (accessed 21 May 2019).

Kuntsman A and Rattle I (2019) Towards a paradigmatic shift in sustainability studies: a systematic review of peer reviewed literature and future agenda setting to consider environmental (Un) sustainability of digital communication. Environmental Communication. Published online: 08 May 2019. Available at:https://doi.org/10.1080/17524032.2019.1596144

Light B (2014) Disconnecting with Social Networking Sites. Basingstoke; New York: Palgrave Macmillan.

Light B (2018) Digital disengagement as everyday practice: interview to the Russian online school of Internet research. Digital Disengagement Stream, May. Available at: http://clubforinternet. net/school_18/current/dd/2/1 (accessed 28 May 2018).

Lupton D (2015) Digital Sociology. London; New York: Routledge.

Lupton D (2016) The Quantified Self. Cambridge, MA: Polity Press.

Mackenzie A (2005) The performativity of code software and cultures of circulation. Theory, Culture \& Society 22(1): 71-92.

Manovich L (2013) Software Takes Command. London: Bloomsbury Academic.

Marwick A (2011) 'If you don't like it, don't use it. It's that simple'. ORLY? Social Media Collective Research Blog, 11 August. Available at: http://socialmediacollective.org/2011/08/11/if-youdont-like-it-dont-use-it-its-that-simple-orly/ (accessed 4 September 2016).

Morozov E (2013) To Save Everything, Click Here: Technology, Solutionism, and the Urge to Fix Problems That Don't Exist. London; New York: Penguin.

Mowlabocus S (2016) Do not disturb: exploring device use among heterosexual couples while at home and on holiday. Project report, University of Sussex, Brighton. 
National Day of Unplugging (n.d.) Available at: https://www.nationaldayofunplugging.com/ (accessed 1 October 2016).

Noble S (2018) Algorithms of Oppression: How Search Engines Reinforce Racism. New York: New York University Press.

Portwood-Stacer L (2012a) How we talk about media refusal, Part I. Flow. Available at: http://www. flowjournal.org/2012/07/how-we-talk-about-media-refusal-part-1/ (accessed 4 September 2016).

Portwood-Stacer L (2012b) How we talk about media refusal, Part II. Flow. Available at: http:// www.flowjournal.org/2012/09/media-refusal-part-2-asceticism/ (accessed 4 September 2016).

Portwood-Stacer L (2012c) How we talk about media refusal, Part III. Flow. Available at: http://www.flowjournal.org/2012/10/how-we-talk-about-media-refusal-part-3-aesthetics/ (accessed 4 September 2016).

Portwood-Stacer L (2013) Media refusal and conspicuous non-consumption: the performative and political dimensions of Facebook abstention. New Media and Society 15(7): 1041-1057.

Portwood-StacerL(2014)Careworkandthestakesofsocialmediarefusal.CriticalPersonas.Available at: http://www.newcriticals.com/care-work-and-the-stakes-of-social-media-refusal/prin (accessed 3 September 2016).

Ritzer G (2015) Prosumer capitalism. The Sociological Quarterly 56(3): 413-445.

Ritzer G and Jurgenson N (2010) Production, consumption, prosumption: the nature of capitalism in the age of the digital 'prosumer'. Journal of Consumer Culture 10(1): 13-36.

Sasaki Y, Kawai D and Kitamura S (2016) Unfriend or ignore tweets?: a time series analysis on Japanese Twitter users suffering from information overload. Computers in Human Behavior 64: 914-922.

Scholz T (2013) Introduction: why does digital labour matter now. In: Scholz T (ed.) Digital Labor: The Internet as Playground and Factory. New York; London: Routledge.

Senft T and Baym N (2015) What does the selfie say? Investigating a global phenomenon. International Journal of Communication 9: 1588-1606.

Straumann RK and Graham M (2016) Who isn't online? Mapping the 'Archipelago of Disconnection'. Regional Studies, Regional Science 3(1): 96-98.

Van Dijck J (2013) The Culture of Connectivity: A Critical History of Social Media. Oxford; New York: Oxford University Press.

Weiser M (1998) The future of ubiquitous computing on campus. Communications of the ACM 1: $41-42$. 